\title{
"Whatever Does Not Kill Me Makes Me Stronger": A Sociological Analysis of Uses of the Concept of Resilience. The Case of Boris Cyrulnik's Self-Help Books Readers
}

\author{
Nicolas Marquis*
}

Abstract: This article offers a social science analysis of the resilience concept's success and common sense uses. Based on a sample of letters from the readers of the French author Boris Cyrulnik's self-help best-sellers, the article first depicts the characteristics of the attitude of the letters' authors towards Cyrulnik and what they expect from him. Second, it proposes to understand resilience as a language game used to communicate about suffering and then analyses why certain readers feel resilient while others don't. It concludes that this way of reacting to adversity (i. e., tapping one's inner resources, never giving up) is particularly desirable in a context where autonomy has become more prestigious.

Keywords: resilience, self-help books, autonomy, suffering, language game

\section{"Was mich nicht umbringt, macht mich stärker»: eine soziologische Analyse der Verwendungen des Konzept der Resilienz. Der Fall von Boris Cyrulniks Lesern}

Zusammenfassung: Der vorliegende Artikel analysiert sozialwissenschaflich die alltägliche Verwendung des Konzept der Resilienz. Basierend auf einer Stichprobe von Briefen der Leser der Selbsthilfe-Bestseller des französischen Autors Boris Cyrulnik zeigt der Artikel erstens, welche Einstellungen die Verfasser der Briefe gegenüber Cyrulnik haben und was sie von ihm erwarten. Zweitens regt der Artikel an, Resilienz als ein Sprachspiel zu verstehen um über Leiden zu sprechen und analysiert dann wieso sich gewisse Leser resilient fühlen und andere nicht. Der Artikel folgert, dass diese Reaktionsstrategie gegenüber Widrigkeiten (die inneren Ressourcen anzuzapfen, nie aufzugeben) in einem Kontext in dem individuelle Autonomie an Prestige gewinnt, besonders wünschenswert ist.

Schlüsselwörter: Resilienz, Selbsthilfebücher, Autonomie, Leiden, Sprachspiele

\section{"Tout ce qui ne me tue pas me rend plus fort ": une analyse sociologique des usages du concept de résilience. Le cas des lecteurs de Boris Cyrulnik}

Résumé: Cet article propose une analyse sociologique du succès et des usages de sens commun du concept de résilience. En se basant sur un échantillon de lettres des lecteurs adressées à Boris Cyrulnik (auteur français d'ouvrages à succès en développement personnel), il dépeint les attitudes et les attentes des lecteurs à l'égard de Cyrulnik. Cet article propose ensuite d'appréhender la résilience comme un jeu de langage permettant de communiquer sur la souffrance, et analyse pourquoi certains lecteurs se sentent résilients, et d'autres non. Enfin, il conclut en observant que cette réaction à l'adversité (puiser dans ses ressources intérieures, ne jamais renoncer) constitue une attitude particulièrement désirable dans un contexte où l'autonomie individuelle a gagné en prestige.

Mots-clés: résilience, ouvrages de développement personnel, autonomie, souffrance, jeu de langage

Université Saint-Louis, CASPER, B-1000 Brussels, nicolas.marquis@usaintlouis.be. 
The concept of resilience is widely used today to describe or to assess the reactions of individuals, groups, or systems to disruptive events. It has the interesting characteristic of being a great success with both the public at large and certain scientific circles.

In the scientific world, this success has given rise to such a number of meanings that a review of the literature has compared it to one of the labours of Hercules (Folke 2006). The very frequently cited definitions include the following - very general - one proposed by Adger (2000) regarding human communities: Resilience is " $[\mathrm{t}]$ he ability of human communities to withstand external shocks or perturbations to their infrastructure, such as environmental variability or social, economic or political upheaval, and to recover from such perturbations." These perturbations can, for example, be linked to various forms of social or environmental disaster (Holling 1973; Norris et al. 2008).

The study of individual and community mental health has been a particularly productive ground for the development of this concept for years (Luthar et al. 2000; Fletcher and Sarkar 2013; Southwick et al. 2014). It was first applied to study how the development of certain children was less impacted by adversity in difficult social, economic, and psychological contexts than other children's (Werner and Smith 1982; Rutter 1985; Masten et al. 1990), gradually gaining legitimacy in a psychiatric risk approach (Masten and Cicchetti 2012), but also more generally to study the conditions of "positive mental health" (Bonanno 2004; Tugade et al. 2004).

Resilience, which is now one of the principal subject of various journals, is still the topic of numerous debates (Richardson 2002; Kaplan 2006; Brand and Jax 2007; Davidson 2010; Ungar 2008; Olsson et al. 2015) because, as Rutter (1999) - one of the most fervent advocates of the concept - proposes, this category crystallises the tensions running through a social, cultural, and moral context to which it is closely linked, making it hard to separate the descriptive or analytical nature of the concept from its moral or normative potential. Depending on how it is used, resilience indeed involves a conception of what a good individual and what a good life are, as well as the ways to achieve these goals. This moral aspect has led to massive criticism, especially in the French-speaking continental Europe, where some scholars try to keep "the scientific value" of resilience safe from the "circus of vendors of happiness" (Tisseron 2005, 6 - see also, for a general presentation of the criticism of the uses of the concept in the mental health area, Ionescu and Jourdan-Ionescu 2010).

While one may question the scientific relevance of resilience, one may also approach it through its popular success, for example in the self-help literature field, ${ }^{1}$

1 To give just a few recent examples: Resilience: Hard-Won Wisdom for Living a Better Life (2015), The Resilience Breakthrough: 27 Tools for Turning Adversity into Action (2014), and 101 Mindful Ways to Build Resilience: Cultivate Calm, Clarity, Optimism \& Happiness Each Day (2016). 
where its moral aspect is even more prominent. This paper focuses on the practical or common uses of the term by individuals who are trying to describe themselves as "resilient." It attempts to provide some elements of the reasons why resilience is so successful by examining the situations of self-help book readers who attach importance to resilience. This implies neither criticism nor celebration of this concept, but a description of its importance from the perspective of those who use it, or, in the words of the pragmatist William James, a description of the difference that it can make in their lives: how does it come about that individuals find it meaningful, worthwhile, and effective to describe themselves as "resilient"?

To answer this question, I shall analyse the ways the readers of Boris Cyrulnik's best-sellers make use of these books and express their feelings about the resilience category through letters sent to the author. Though it cannot claim to be representative of any use of resilience (even in the mental health or self-help area), this field is significant, as Boris Cyrulnik has been popularising resilience in European French-speaking scientific and popular circles for the past twenty years, to the point that his works are both must-read references in the mental health field as well as best-sellers in the self-help books category. The concept of resilience is clearly associated with his name in the French-speaking parts of Europe today. Moreover, the subject of resilience, as it runs through Cyrulnik's writings, ties in with some of the characteristics already observed in other widespread discursive forms related to misfortune and illness (Sontag 1990; Frank 1995; Carel 2008) or, even more recently, to voice-hearers (Woods 2013).

The first section of this article gives a brief overview of how Cyrulnik makes use of resilience in his publications. The second section presents the corpus compiled to analyse the ways certain readers use resilience themselves. In the third section, I discuss the attitudes adopted by the writers of the letters and how they see their relationship with Cyrulnik. Finally, in the fourth and last section, I propose to study resilience as a language game (Wittgenstein 2010), that is to say, a set of terms to be understood from the ways that they are used and considered as important by individuals struggling with situations of suffering and distress.

\section{An "extra-ordinary" life: resilience according to Boris Cyrulnik}

Boris Cyrulnik, who was inspired by ethology as well as the clinical studies of attachment (Bowlby 1958), presents himself as an ethologist, a neuropsychiatrist, and a resilient person. He has written a number of commercial successes, including Un merveilleux malheur (1999) and Les vilains petits canards (2001), with some 500000 copies sold for each book. A dozen other books, devoted roughly to the same topic, have been published in French to date, with similar publication runs. 
More recently, he has also written books published in English, such as Resilience: How Your Inner Strength Can Set You Free from the Past (2011).

How can you have hope when you are in despair? What can you do to recover when you have been traumatised? These are the types of questions that Cyrulnik's books claim to answer. Resilience, he says, is "the ability to succeed, to live, and to develop positively, in a socially acceptable manner, despite stress or adversity, which usually carries the serious risk of a negative outcome" $(1999,8)$. In other words, it consists in "resuming a type of development after psychic agony" $(2004,44)$. In the vitalist anthropology, supporting the author's perspective, resilience is a process which is possible for everyone, because it is psychologically ingrained in us (it is a "neural good, first of all" [2006, 118]). It leads to a lifestyle of special, serious, and extraordinary quality. However, it does not kick in automatically; it is triggered under certain conditions only.

The first condition is: "to be resilient, you must have been traumatised first" (Cyrulnik 2001, 231). The illustrations he gives (rape, abuse, concentration camps, etc.) lead one to believe that, first and foremost, resilience involves a very serious trauma. Suffering is "the golden ticket" to obtain the label of an extraordinary life: you can claim this way of existing, which distinguishes you from those who live normally, because you have suffered. Those who have been traumatised understand, whereas the rest live their daily lives superficially: “... those who have been maimed by the past can teach us something" $(2001,28)$. Next, "tutors of resilience" must be stationed around the traumatised person. These can be trusted people, masters of wisdom, benevolent institutions, etc., who will enable the traumatised person to reconnect with the world after having suffered violence. Finally - and this is the most important step - it is essential for the traumatised person to start working on the meaning of this traumatic experience. Otherwise, s/he will not be able to go beyond it. This work makes it possible to give oneself areas of freedom again, thanks to an "emotional re-arrangement [by the subject] of how s/he sees her/his wound" $(2004,169)$, although his books remain rather hazy about the way this work must be done. Cyrulnik admits the resolute optimism throughout the process he describes, but also the contradictions that it may entail with regard to what he calls the "surrounding culture."

... training oneself mentally to acquire new relational skills, working on the past that makes up our identities, learning to think of oneself in different terms and to fight the stereotypes that [our] cultures recite about the wounded - that is how the ethical commitment of resilience can be summed up. (Cyrulnik 2004, 119)

You can remain dead. That is the most comfortable solution; it is even the one that our culture accepts most readily. "After what happened to him it is clear, he is ruined for life." Too much compassion condemns one to 
mental death, and if, unhappily, you fight to return to life, you run the risk of creating a scandal: "What? He went dancing? He was happy when he came back from the cemetery?!" (...) Resilience is suspect, don't you think? (Cyrulnik 2004, 243)

\section{Methodology}

The corpus consists of 97 letters, all of which were addressed to Boris Cyrulnik personally and obtained from him directly in 2009. For this purpose, I met Boris Cyrulnik twice, and I asked him if he would agree to give me about 100 letters he had received from his readers, and only from people whom he did not know personally. He picked these 97 letters himself, while I was there, from a folder containing a large number of them. According to our agreement, these letters would be rendered totally anonymous, re-transcribed, and then destroyed.

The resulting corpus was broken down into the five following categories: the first and largest group (39 letters) focused on the category of resilience per se as their main subject. Of this group, 16 were written by readers who wanted to tell the author how they saw themselves as belonging to the resilience category, 9 contained criticism of the concept of resilience, and, finally, 5 letters were neither critical nor laudatory and contained requests for clarification as to the possibility of applying resilience to their own case. A second group (24 letters) contained calls for assistance to deal with situations of psychological or moral distress, most of them from individuals who had read one or more of Cyrulnik's books and had mobilised the concept of resilience more peripherally. 6 of them concerned the writers of the letters themselves, whereas the other 16 concerned a third party (often someone close to the writer of the letter). A third group (18 letters) had in common that they contained various requests which had nothing to do with resilience and therapy, with few exceptions. These included requests for prefaces, loans, participation in a think-tank, and so on. A fourth set (9 letters) were attempts to engage Cyrulnik, as a public figure, in controversies, whether private (for example, trying to recover custody over one's children or refusing to be certified/interned in a hospital ward) or public (socio-political issues, working to have osteopathy recognised, etc.). Finally, a fifth and last set (9 letters) consisted of letters which were fragmentary or difficult to understand, making their sociological interpretation too hazardous. Only the first two sets of letters, concerning resilience, either directly or indirectly, were considered to meet the needs of this analysis, for a total of 63 letters.

All this material, which is part of a broader set (consisting of 55 face-to-face interviews of self-help books readers and 295 letters), was then subjected to content analysis, borrowing from grounded theories (Glaser and Strauss 1967). A first manual coding on paper (i.e. identifying meaningful units of the 335 letters and 
interviews) enabled us to build a first inductive grid, where these were hierarchically aligned with one another. This coding grid was also inserted into the NVivo software, alongside the interviews and letters for the second coding. The final coding grid consists of 264 hierarchical codes, each grouping an average of 8 "pieces" of letters or interviews, for a total of more than 2000 coded elements (for a complete presentation, see Marquis 2014, 201-206). This article reuses part of this material (the letters of Cyrulnik) for a question which was not raised in the analysis of 2014: the question of the applications of resilience.

The original aspect of this material implies using it with caution and requires us to deal with two questions first: what does this material tell us? What are the risks and benefits of working on it from an ethical perspective?

First, this material should not be considered as representative of all the letters received by Cyrulnik, nor of all the readers of his books. Indeed, if Cyrulnik picked this sample of letters randomly from a much bigger folder while I was there, I have absolutely no certainty that the said folder was containing all the letters he received. However, the variety of the discussed topics we mentioned earlier and the presence of positive but also negative comments on resilience enable us to be quite confident that this sample covers a large range of the received letters, especially letters criticizing resilience. It is even more important to insist on the fact that an analysis of the readers' letters cannot claim to speak on behalf of all the readers of Cyrulnik's books (especially of all the ones who don't bother writing). Drawing on Bakthin, Norman Fairclough insists on the necessity of taking into account the "kind" of productions which are under investigation, in the discourse analysis (see for example Fairclough 2013, 174). In this specific case, going through the letters enables us to find reports of readers who are in a very particular situation, the one of a request to a willful person: the author. Indeed, almost all 97 letters contain a request (even if they don't imply the expectation of an answer from Cyrulnik, but more as a request to be merely read and share their experience). Generally, the writing of a letter to a famous author, who is often admired for his writings and most of all for what he has created, appears to be a very engaging process for the readers. The letters show that the writers are studying themselves while they are writing and share how important this letter is for them and how it creates emotions and even has therapeutic effects, as seen in the end of this letter to Cyrulnik:

I felt a strong emotion writing this letter and the expectation of an answer, that I don't anticipate, is none the less... Hoping that you will duly receive this letter, with my sincere appreciation and consideration, Doctor. ${ }^{2}$

Letters are a means of expression, where individuals feel more comfortable, because they often suppose that the author, with whom they sometimes experience a sense of community, will be able to accept and understand the extent of the experience

2 We have translated the excerpts of the readers' letters, most of which were written in French. 
which can be felt in his books. So, this is very specific and it does not allow us to deduct the experience of the readers who are not using it. But, at the same time, these particularities make this type of material interesting, compared to more classical discourses (such as research interviews). Not only is it rich with information about the pragmatic and performative uses of resilience (Alexander 2004), but it is also less subject to the bias of social desirability (Marquis 2015).

Second, this type of research material (also used by Simonds [1992] in his analysis of the self-help books) raises specific ethical questions. On one hand, it was not created to be read by a researcher. On the other hand, its use does not imply an "informed consent," because the information to contact the authors of the letters, when there were any, was immediately destroyed, as required by the agreement made with Boris Cyrulnik. I would like quickly to raise a double question: on one side, may the applied process harm some people? On the other side, why is this really worth it?

Regarding the first question, numerous precautions have been taken to minimize, even eliminate, the consequences of this breach of confidence concerning in the use of material without an informed consent. First, the anonymization of the material is total here: it concerns the personalizing elements (such as the age or the first names) but also the elements which are potentially personalizing (such as the job, the region, the number of children, the name of the reported diseases), etc., so that it is reasonably impossible to connect the reproduced material to an individual. In this analysis, the identification information is irrelevant because the discursive forms matter. What is more, there was a relatively long period of latency since the most recent letters are from 2008.

Is it worth it? From a scientific perspective, describing a reading process is complicated (Macé 2011), and the researcher has to refer to reports from the readers. I mentioned earlier what were the particular advantages of this kind of readers' mail. From an ethical perspective, I think that the use of this particular material can also benefit the readers themselves. Indeed, the research in social sciences about that subject lacked the social and moral consideration of the readers' work, which led to the creation of a less real and friendly typical reader on whom unilateral theses are based (Marquis 2014). Since we are in a situation where propositions without (or little) empirical support prevail, the readers can surely benefit from research which bothers to make a detour within production by studying the reception processes as honestly as possible.

The analysis of the letters from Boris Cyrulnik's readers immediately reveals a particularly striking element, namely, the very high emotional charge which accompanies the possibility or impossibility of using the term "resilient" in the person's specific case (or in the case of a close contact with the respective person). As Wendy Simonds points out regarding similar material, this emotional charge "indicate[s] that the authors' arguments were perceived as deeply meaningful” $(1992,81)$. The 
largest portion of the letters sent to the author comes from individuals who were overjoyed to find themselves to be resilient:

I am a reader who has been deeply moved by your writings, especially by your book on resilience. You know how to put what hurts us into words, and your description of distress mirrors my own distress.

Other authors of letters, on the contrary, tell Cyrulnik about their doubts or their disappointment about not feeling that they belong to the category of the resilient, for example because they feel unable to find a positive way to extract themselves from the clutches of distress or suffering, despite their many attempts to pull free, as the following excerpt shows:

Dear Sir,

(...) I "freeze" despite my appearance (...) I can't seem to reach that unconditional state advocated by the most expert of "shrinks," perhaps, [that of] the "resilient." The approach of Saint Valentine's Day exacerbates my feeling of isolation, of being different (...) You may ask why I am writing to you? Doubtlessly because I want to give you a lesson in humility, but I am searching above all for an opening. I live my life, struggling along, without finding the door that will prevent me from returning to the past. (...) No, I am not alive!

This emotional charge can be explained at two levels (which are mixed in reality). The first one relates to the typical positions in which the people who wrote these letters find themselves by addressing the author of a book they read, in order to feel better or to change their lives. The second one is linked to the fact that the category of resilience is used to give a grip on and make sense of negative experiences that have often caused what people experienced as major suffering or distress.

\section{$4 \quad$ Writing a letter to the author of a self-help book}

Readers, who are inclined to read personal development or self-help books are constantly asking themselves the following questions: what does the book say about me? What can I learn from it about my life, my distress, the way I behave? How must I interpret my symptoms, etc.? (Marquis 2014; Lichterman 1992). These transactions with the book encourage the readers to try to put their life experiences in tune with the book. Moreover, they suppose that the assumption that Cyrulnik and his books potentially have something to say about themselves has been activated. The reading itself is not done lightly because it is often governed by expectations of effectiveness (finding a way of shaking something off, of feeling better), and also because it seems to give the reader and the writer of the book an important power, 
that of saying what is going on. Indeed, many of the readers, some of them hoping to get an answer from Cyrulnik, fill their letters with what may be likened to requests for appraisal (from someone whom they consider an expert on life) of the nature and quality of what they are going through.

Mr Cyrulnik,

My wife and I have taken the liberty of writing to you about our forty-fouryear-old daughter, Jacqueline, who went deaf very quickly eleven years ago. Could you, with the help of the photocopy of Doctor X's report, give us your opinion about the following question, for which we should be grateful: Could an emotional issue that she experienced in her adolescence (a temporary conjugal problem) be the cause of her illness? (...)

(41) Dear Mr Cyrulnik,

You will most certainly find my approach very cavalier, but after months of hesitation, I have finally looked for your address to write to you. (...) Yes, here are all my questions. What are the shares of genetics, of instilled fear, of the reproduction of the family member crises that I witnessed? Am I truly a low producer of serotonin, as you say? Or must I continue therapy until my Jewishness is no longer a burden of suffering? And what about my son? Is he doomed to experience such anxiety as well? I'd like to be told that if these substances help me, well, all the better, and then I'll take them my whole life, if necessary, but won't I become addicted to them and need higher and higher doses until they fail to have an effect on me? ...

Dear Sir,

... is my balance sufficiently stable?

thank you for your attention.

With great esteem.

Thank you in advance for your answers.

As the above excerpts show, the readers have various types of requests to Cyrulnik. The first two excerpts reveal questions about the "nature" per se of the malaise or "ill-being" which takes two forms: first comes the attempt to understand the type of cause-and-effect relationship at play (is it a neurological, systemic, relational, or another type of problem?). Next, and as a result, these people ask Cyrulnik how they can assign responsibility for their misfortunes (to themselves and/or to others). The question is about knowing who or what is responsible for what has happened and where the blame lies: are we responsible for our daughter's deafness? Can my breakdown be explained by my family history and my Jewishness or by a low level of serotonin? Is it due to my brain or my ancestors?

These questions, in which their authors try to find landmarks to parametrise their situations - and in which they provide many descriptive elements, probably in 
the hope of helping Cyrulnik to give the most appropriate answer to their case - are far from theoretical. On the contrary, they are very practical, for they determine the types of action that the individuals may take. The questions about what is going on also concern the right actions, what must be done, as attested by the last two letters (should I take medication? Is my [mental] balance sufficiently stable?).

The characteristics of the readers' attitudes are a first clue to understanding the emotional charge which permeates the letters. One cannot stress too much how significant reading books such as Cyrulnik's is for many readers: reading them proves to be a meaningful practice by people who are expecting something, usually because they are in distress (or are the witnesses of someone else's distress).

\section{Resilience as a language game to communicate about and cope with suffering}

The theme of suffering or distress runs through almost all the letters written to Cyrulnik. Whether it's a matter of presenting the writer's own painful experiences, enrolling the recipient in a controversy because the sender feels that her/his distress is not reflected on appropriately, asking questions about the relevance of the categories of trauma and resilience to describe a painful life experience, or even those countless "calls for help," i. e., letters tossed out like "bottles tossed into the sea,": suffering is omnipresent.

Mr Cyrulnik,

In my search for the author of "Les Vilains Petits Canards" [Cyrulnik's book], amongst many other things, I do not know if I am writing to the right person. (...) I suppose that you must receive tons of letters from your admirers and I am one of them. Your books helped me to look at things from a different angle during a very difficult period of my life.

In the two groups of letters which interest me, the aim is more specifically to communicate with Cyrulnik about some types of suffering, because either the writer feels that the concept of resilience makes it recognisable or the writer wants to have Cyrulnik recognise the suffering.

The possibility of talking about one's suffering is an extremely interesting issue from a sociological perspective, because it forces us to focus our attention on the language games which are used by the individuals who want to express their suffering verbally. As Stanley Cavell (1979) and Pierre-Henri Castel (2012) have shown, our different ways of suffering or hurting are closely linked to how we express this suffering or malaise in words. This has two consequences. On one hand, communicating about suffering carries a risk: because this communication can succeed or fail, the suffering may be recognised or, on the contrary, denied. On the other 
hand, the forms of expressing suffering necessarily take on the cultural categories that are more or less within the individual's immediate grasp ("ordinary language"). The categories of trauma (Fassin and Rechtman 2007), survival (Orgad 2009), and resilience are part of this whole. They are used by individuals who are practically led to answer such basic questions as "have I suffered a lot?," "Is my suffering similar to the one of others?," "What meaning does my suffering have?," "How does one reweave the fabric of ordinary life after a major negative attempt?" or even "How can I know if my life is worth living?"

This interest is reinforced even more in individualistic societies (Dumont 1985; Ehrenberg 2010) because, in such contexts, suffering is given a special status. Since the advent of modernity, the subject is "defined by this very claim, that of ,knowing oneself' better than anyone else, the claim of having the priority to access one's own psychological states" (Laugier 2013, 173 [own translation]). The matter of pain experienced as something fundamentally internal and private then becomes decisive in the problem of access to the self. It is considered to be the quintessence of the monopoly the individual has on knowledge of her/his internal state. As Wittgenstein says, it is true that it makes sense to say that others doubt I'm hurting and there is no sense in my expressing such doubts about myself (Wittgenstein quoted by Laugier 2013, 173). I know without a doubt that I am suffering and no one else can claim to know that better than I do. However, at the same time, the suffering exists only through the way it is expressed or manifested: suffering has an internal, logical relationship with its expression, whether this takes the form of grimaces and tears of pain, oral or written testimony, active areas in brain scans, etc.). Moreover, as we have just seen, expressing suffering is, at the same time, a request for its recognition by others: I expect the other person not only to understand, but also not to be indifferent (Das 1998). From this perspective, expressing suffering requires the use of external criteria. Otherwise, it will be recognisable neither to others nor to the individual her/himself (this is why we might say, according to Wittgenstein, that it is impossible to have a private language of suffering).

This creates a potential paradox, which the people who read Boris Cyrulnik's books and take the time to write to him will experience very differently. This paradox may be expressed as follows: I alone truly know my suffering, but I need it to be recognised by someone else for it to exist.

On one hand, the readers obstinately cling to the idea that their suffering is internal and claim that you need to have lived through it to be able to talk about it. Moreover, they readily value Cyrulnik's expertise on this same level of personal life experience:

Dear author,

I'd like to thank you for BEING and tell you how much what you ARE, what you have LIVED THROUGH, and what you have DONE with what is important for me, a grain of sand on an immense beach. 
On the other hand, however, through their readings, they search for shared categories which are external to themselves and do not depend on them to qualify (what am I going through?), quantify (is it a lot of suffering?), and evaluate (is it serious? Is it normal?) their suffering and their ways of reacting to it. However, the use of these categories entails following certain socially shared rules, if not, it will be deemed inappropriate, even mad. Regarding the idea of word games, Peter Winch stresses the importance of rule-following, stipulating that...

...one has to take into account not only the actions of the person whose behaviour is in question as a candidate for the category of rule-following, but also the reactions of other people to what he does. More specifically, it is only in a situation in which it makes sense to suppose that somebody else could, in principle, discover the rule which I am following that I can intelligibly be said to follow a rule at all. (Winch 2009 [1958], 86)

For example, it is hard for me to claim seriously that I am "going through trauma" by explaining that I have an ingrown toenail. In such a case, it is highly unlikely that what I claim to be traumatic will be recognised as such by others. Even if I argue that I am the only one who can really know how I am suffering, I cannot decide all alone, without following the rules that must be applied, that my experience is traumatic, or I will be seen as mad. And the contrary, i. e. showing myself to be almost unaffected by a life experience which will usually be considered as traumatic, will also trigger questions about my mental health, even if I argue that I am the only one who can judge that "it didn't affect me."

The reader who tries to better understand her/his life experience by making use of the resilience category must thus answer the following question: to what extent is it legitimate to use someone else's words and socially shared and valued categories (resilience in this case) to be able to qualify for a path of suffering and see it recognised, and even valued? By writing to Cyrulnik, because they feel resilient or would like to be, the readers ask him - thus putting him in the position of adjudicator of this category - to recognise their right or the soundness of applying the category of resilience to themselves.

\subsection{Feeling oneself to be characterised by resilience}

Those individuals, who feel that they are resilient and identify with Cyrulnik's descriptions do not take this paradox as a threat. On the contrary, there is a more or less perfect overlap between their life experiences and the label "resilient."

Mr Cyrulnik,

(...) a few months ago, my wife gave me the first book you wrote, "De chair et d'âme", a book which will remain a turning point in my existence. Something grandiose took place in me very early on during my reading of 
this book. You wrote with everyday words what I had never managed to express simply. (...) I was very quickly won over by the fact that, all of a sudden, something made sense in my mind, "The Right to be Different." That difference that no one sees because appearances are so deceptive (...) and I have discovered that I, too, have the right. (...) There is absolutely no doubt about it; I have discovered that I am no longer part of an isolated, unknown world (more for everyone). I recognised myself completely in the category that brings together those "Gueules Cassées de la Carence Affective" [an expression used by Cyrulnik which means: "the Wounded from an Affection Deficit"]. (...) Reading your books makes me hope for a peaceful future for the next 20 or 30 years (or more, perhaps).

Mr Cyrulnik,

My life is far from unique, as you have shown. But, as you wrote in one of your books, the "resilient" are not counted, they are not spoken about. In setting down my pathway in writing, what I want to say is that this resilience is possible. You said it before me!

Mr Cyrulnik,

I am writing to you because I want to give you, on a platter, the episodes of a struggle waged by a resilient person, who was unaware of this quality.

The people who feel characterised by resilience express their gratitude to Cyrulnik for knowing how to put words to what was hurting them, to use a French phrase ("vous savez metre des mots sur les maux") which cropped up time and again. Feeling that they are resilient matters to the readers, because it enables them to break out of their isolation and feel attached to a community of people "who have been through that" (with Cyrulnik himself leading the list). Being able to use the words that someone else has written to describe themselves seems to mean, for his readers, that Cyrulnik recognises their distress and journeys through life, which they think the rest of society ignores.

In such instances, the readers use phrases of complicity with the author, who seems closer to them because of a story they experienced as similar, ("Boris, I wanted to get in touch with you for years. I use this familiar form of address because we share a common history") often using euphemisms, litotes or understatements, which shows that they have nothing left to prove, since they think that Cyrulnik recognises their suffering:

What is more, I wanted to share my experience with you for I believe that I, too, have used life's trials as a force for tomorrow (...) My childhood was not one of the happiest; I grew up in a climate of conflict, humiliation, denial, and violence. (...) I did not eat my fill and everything was taboo and forbidden. (...) At the age of 13, following my sister's lead, we ran away, 
my sister dumped me along the way (...) A 16 I was raped and tortured a little, I hid it from everyone...

Finally, the importance of being described as resilient is not solely to have one's past suffering recognised. It offers a future for a current experience which is more or less (dis)satisfying: "Your book opened doors for me, as much in the understanding of my own past as in my way of envisioning the future," "Reading your books gives me the omen of a peaceful future for the next 20 or 30 years (perhaps even more)." The story into which the readers' lives are reincorporated is the optimistic one of those who have already "been there" and can tell the tale (Cyrulnik also avails himself of such arguments, like many other authors of self-help books): it is possible to pull through.

\subsection{Not feeling oneself to be resilient}

The request for recognition, which in this case takes the form of being judged resilient, can, however, fail, and the paradox mentioned above is then felt much more acutely by the writers of the letters. Yet, all of the letters which expressed doubts about or criticised the notion of resilience came from people who, with no exceptions, would like to call themselves resilient. Two cases can be discerned within this group. In the first one, the individuals say that they should be considered resilient but, after reading Cyrulnik's book(s) (or listening to one of his speeches), feel that Cyrulnik would not give them that right. The second consists of people who, as in the following excerpt, do not consider themselves resilient and criticise the concept for being too smooth. It is interesting to note that even without (or before) an answer from Cyrulnik, the writers of the letters already have an opinion on what Cyrulnik might think of their case.

I simply wanted to say that, while the concept of "resilience" is rather optimistic and hopeful, it isn't that simple. (...) To sum up, my reproach is that you speak only of those who are resilient and never of those who don't make it, despite their awareness and desire to be helped to pull through and also that you hide the not always very pretty means that some people have used to be resilient.

The writers of the letters, who do not feel that they can be called resilient, mention two insufficiencies, which can be linked to two conditions Cyrulnik is referring to in his description of resilience (one must have been traumatised and one must have worked on one's suffering). On one hand, they may have the impression of not having suffered enough to deserve the label of "resilient." As Stanley Cavell (1979) shows, expressing suffering always carries a risk, for if it fails to be shared, it is likely to lead to a practical experience of scepticism (in which the individual who expresses her/his suffering gets a reaction along the lines of "how does that prove that you are 
suffering? What you went through is perhaps not so serious, it's nothing"), but also a feeling of exclusion. As Cavell explains, if our words are to continue to mean what they want to mean, other people must be willing to take the trouble to continue to understand us, because if they might see a better deal elsewhere, they might decide that we were no longer part of their world, from which it would appear that our mental health depended on whether they approved of us, whether they found us to their liking (Cavell as quoted in Das 2013, 159). As the following excerpt shows, the people who find themselves in this situation provide a very detailed description of massive symptoms of suffering and solitude (where other readers make do with an understatement because, given their feeling of belonging to a community, they no longer need to prove themselves):

Hello,

(...) I felt so bad to hear that so many people (especially famous ones) who had been severely traumatised were able to be resilient while I can't. I have not experienced any serious one-off traumatic events. No rape. No incest. Not deported. Not beaten. After my companion and I separated, I had a severe breakdown. (...) Often, in the evening, when I go to bed, as I fall asleep, I say, "if only I might not wake up." And each morning for almost 30 years now, I am terribly oppressed, crushed, immobilised by intolerable sadness. I tell myself "one more day to grapple with ..." I feel as if I am sentenced to live, I feel guilty for existing. (...) I'd like to stop suffering. But without affection (...), no one to confide in (except my shrink), it's hard. Some of my friends have tried to convince me to tell them when I'm feeling down. But I can't. I'm ashamed. (...) When people ask me how I'm doing, I always force myself to answer, "I'm OK." I'm very talented (at least there's that) when it comes to fast retorts.

Suffering from suffering, walled in within a vicious circle of pain that I have never been able to stop, I am tortured by my past. I don't know how to get rid of it or accept it. How to live in peace. I'd like to get myself out of there, but I have no idea how to go about it.

Dear Mr Cyrulnik,

(...) I feel so alone, at such a loss, that I am counting on your generosity to forgive me for my audacity. (...) There are moments in life when the emptiness makes you dizzy.

On the other hand, they mention the problems they have to overcome their suffering, to rebound in order to make something out of their suffering. Whereas the people who recognise themselves as resilient mention the joy of an open future over which they are once again in control, the readers who do not feel empowered to call 
themselves resilient talk about a feeling of going nowhere and put forward figures of passiveness, with the feeling of being a "victim" or "dependent" on top of the list:

Sir,

(...) I'll soon be 59 years old, I'm still a victim, despite myself. I am quite aware that I am unable to grow up. The past always catches up with me and amputates a part of the present.

I'll soon be dependent on shrinks for 30 years. And I can't stop thinking that if I can't be resilient, it is because I am a looser. Once again.

\subsection{Resilience as a way of working on oneself}

As the mirror excerpts of letters from people who have and have not managed to call themselves resilient show, what matters to the readers are the new possibilities of meaning and action that the language game of resilience opens up. This language game must make it possible first to qualify their woes, to "de-individualise" the readers' experiences and to make them part of a community.

However, what matters above all to these individuals is the fact that being deemed resilient opens the possibility to a different future, to an improvement, by making it possible to translate the solution to the problems or misfortunes that they are experiencing in such a way that they can do something about it them themselves. The fundamental question haunting the readers who hope for efficiency is, "what can I myself do to pull through?" The language game of resilience enables one to stress the fact that the room for manoeuvring is never nil and it is incumbent on each of us to use these inner resources to take the first step (even if it consists of asking for help):

Mr Cyrulnik,

I've read your books on resilience very carefully. They helped me with my personal development a great deal at a time when I refused to consult a psychologist, until the day when I had to accept that I needed a therapist to move forward.

The language game of resilience does this translation on the level of individual action through a particular way of assigning responsibility. It is interesting to see that, as a rule, the readers subscribe to a disjunction which is very present in the language game of resilience: while the causes of their sorrows are often out of the individual's reach (e. g., other people, an accident, a toxic family context, a geopolitical situation, even the brain's chemistry), the solutions to them are considered to be at least partly, if not completely, dependent on each individual. Responsibility for misfortune is externalised; responsibility for pulling through is internalised. Cyrulnik's quote and the reader's remarks which follow seem to correspond perfectly from this point of view: 
But, to think in terms of resilience, one's life history must first be turned into a vision in which each encounter is an existential choice. This way of giving non-inexorable sense to one's life attests to a capacity for inner freedom. It authorises a thousand possible scripts, with the hesitations, lucky breaks, and anxiety that all choices trigger (...). This little freedom is a craft where each gesture and word can change the reality that pulls us along and build resilience as a bulwark against fate. (Cyrulnik 2004, 48)

Mr Cyrulnik

(...) I am reading Un merveilleux malheur and the concept of "resilience" has affected me enormously. It affects me because you truly have to look at things positively as you go through life, even if you experience negative events. That is not only encouraging, but real, possible. There is also a personal reason, for I went through a traumatic experience when I was 10: I lost my whole family in a car accident. That was very difficult. However, upon reading your book, I became aware of the fact that I had started to live, without knowing it, this process of resilience that you describe.

As these two excerpts show, resilience makes it possible to call upon ideas of choice and will, which the readers readily embrace for their own purposes. Using resilience subordinates "being able to" to "wanting to": on one hand, you can pull through only if you want to, but on the other hand, where there is a will, nothing is impossible ("where there's a will, there's a way"). Each of us has to choose whether to cave in or to fight.

\section{Conclusion: resilience as a way of being affected correctly by adversity}

Cyrulnik's readers thus seem to subordinate knowing what they have (their experiences, suffering, etc.) to identifying with the descriptions in the book, which implies being recognised by the author of these descriptions. For the people who take the trouble to write to Cyrulnik, reading this type of book is not a pastime that is easy to drop if, instead of putting the book back on the shelf when they fail to identify with it, they write to the author to state their disagreement or the feeling of helplessness which arises from their disconnection with the text.

The language game of resilience can be likened, in this sense, to what Peter Winch called an "attitude towards contingencies," i. e., a way of "dealing (symbolically) with misfortunes and their disruptive effect on a man's relationships with his fellows, with ways in which life can go on despite such disruptions" $(1964,321)$. This language game is not the only existing one. However, I would like to wrap this up with a hypothesis that its success and the desire that individuals express to participate in this special form of life, that of the "resilient person," stem from its 
particularly prestigious nature. When one faces misfortune, being and not being resilient are not choices. Not being resilient is taken as a failure, whereas being resilient is a desirable state. Resilience definitely includes an evaluative dimension, i. e., a value judgement.

This prestige has to do with the affinities that this language game has with the values that Ehrenberg calls a "society of autonomy as a condition" (Ehrenberg 2010): to stress that the individual's autonomy as the supreme value of our collective representations is no longer an aspiration, but actually a common expectation, both from ourselves and from others. In other words, acting upon oneself is highly valued in such a society as a rule to follow, and the legitimate question that each person is urged to ask himself when confronted with misfortune is "what can I do to pull through?"

Resilience is a way of reacting to misfortune which, when confronted with the ordeal, values action stemming from each individual's own resources, at the detriment of passion, lamenting, and waiting for solutions from other instances. It carries the idea that it is always possible for us to do something in response to what happens to us, even if it is only changing the way we look at our situation. The readers seem to share Cyrulnik's democratic anthropology, according to which we all have the resources which enable us to overcome misfortune of whatever kind. Even the readers who complain that they are unable to describe themselves as "resilient" seem to agree with the idea that it is up to them to do something about it. As a result, passive attitudes such as sadness, boredom, silence, repetition, and, even more so, the attitude of "complaining" and the position of "victim" are devalued, even made incomprehensible, based on the pretext of their unproductiveness.

Resilience is thus a language game which offers a way to be "affected correctly" by the surrounding world, or to react to contingencies correctly, by turning passion into action. Not only does it enable the reader to think that s/he can do something about her/his misfortune by translating it into something that is within her/his grasp, but it is also a resource for thinking that each of us can do something with our respective misfortunes, in order - hopefully - to live not despite them, but thanks to them.

\section{$7 \quad$ References}

Adger, Neil. 2000. Social and Ecological Resilience: Are They Related? Progress in Human Geography 24(3): 347-364.

Alexander, Jeffrey. 2004. Cultural Pragmatics: Social Performance Between Ritual and Strategy. Sociological Theory 22: 527-573.

Bonanno, Georges A. 2004. Loss, Trauma, and Human Resilience: Have We Underestimated the Human Capacity to Thrive After Extremely Aversive Events? American Psychologist 59(1): 20-28. 
Bowlby, John. 1958. The Nature of the Child's Tie to His Mother. International Journal of Psychoanalysis 39: 350-371.

Brand, Fridolin S. and Kurt Jax. 2007. Focusing the Meaning(s) of Resilience: Resilience as a Descriptive Concept and a Boundary Object. Ecology and Society 12(1): 23.

Carel, Havi. 2008. Illness. Durham: Acumen.

Castel, Pierre-Henri. 2012. La fin des coupables. Paris: Ithaque.

Cavell, Stanley. 1979. The Claim of Reason. Oxford: Oxford University Press.

Cyrulnik, Boris. 2006. De chair et d'âme. Paris: Odile Jacob.

Cyrulnik, Boris. 2004. Parler d'amour au bord du gouffre. Paris: Odile Jacob.

Cyrulnik, Boris. 2001. Les vilains petits canards. Paris: Odile Jacob.

Cyrulnik, Boris. 1999. Un merveilleux malheur. Paris: Odile Jacob.

Das, Veena. 2013. Institutions psychiatriques et vies singulières. La maladie mentale en contexte de pauvreté urbaine. Pp 135-160 in Face aux désastres. Une conversation à quatre voix sur la folie, le care et les grandes détresses collectives, edited by Anne M. Lovell, Stefania Pandolfo, Veena Das, and Sandra Laugier. Paris: Ithaque.

Das, Veena. 1998. Wittgenstein and Anthropology. Annual Review of Anthropology 27: 171-195.

Davidson, Debra J. 2010. The Applicability of the Concept of Resilience to Social Systems: Some Sources of Optimism and Nagging Doubts. Society and Natural Resources 23(12): 1135-1149.

Dumont, Louis. 1985. Essais sur l'individualisme. Paris: Le Seuil.

Ehrenberg, Alain. 2010. La société du malaise. Paris: Odile Jacob.

Fairclough, Norman. 2013. Critical Discourse Analysis. The Critical Study of Language. London: Routledge.

Fassin, Didier and Richard Rechtman. 2007. L'empire du traumatisme. Enquête sur la condition de victime. Paris: Flammarion.

Fletcher, David and Mustafa Sarkar. 2013. Psychological Resilience: A Review and Critique of Definitions, Concepts, and Theory. European Psychologist 18(1): 12-23.

Folke, Alan. 2006. Resilience: The Emergence of a Perspective for Social-ecological Systems Analyses. Global Environmental Change 16: 253-267.

Frank, Arthur. 1995. The Wounded Storyteller. Chicago: University of Chicago Press.

Glaser Barney G. and Anselm A. Strauss. 1967. The Discovery of Grounded Theory: Strategies for Qualitative Research. Hawthorne: Aldine de Gruyter.

Holling, Stanley C. 1973. Resilience and Stability of Ecological Systems. Annual Review of Ecology and Systematics 4: 1-23.

Ionescu, Serban and Colette Jourdan-Ionescu. 2010. Entre enthousiasme et rejet: l'ambivalence suscitée par le concept de résilience. Bulletin de psychologie 510: 401-403.

Kaplan, Herbert. 2006. Towards an Understanding of Resilience. A Critical Review of Definitions and Models. Pp. 17-83 in Resilience and Development: Positive Life Adaptations, edited by Michael Glantz and Johnson, J. New York: Plenum.

Laugier, Sandra. 2013. Veena Das, Wittgenstein, and Stanley Cavell. Le care, l'ordinaire et la folie. Pp 161-185 in Face aux désastres. Une conversation à quatre voix sur la folie, le care et les grandes détresses collectives, edited by Anne M. Lovell, Stefania Pandolfo, Veena Das, and Sandra Laugier. Paris: Ithaque.

Lichterman, Paul. 1992. Self-Help Reading as a Thin Culture. Media, Culture \& Society 14: 421-447.

Luthar, Suniya S., Dante Cicchetti, and Bronwyn Becker. 2000. The Construct of Resilience: A Critical Evaluation and Guidelines for Future Work, Child Development 71(3): 543-562.

Macé, Marielle. 2011. Façons de lire, manières d'être. Paris: Gallimard. 
Marquis, Nicolas. 2015. Allowing for Social Desirability in Reception Studies. The Case of Self-Help Book Readers. Bulletin of Sociological Methodology 127(1): 58-71.

Marquis, Nicolas. 2014. Du bien-être au marché du malaise. La société du développement personnel. Paris: PUF.

Masten, Anne S. and Dante Cicchetti. 2012. Risk and Resilience in Development and Psychopathology: The Legacy of Norman Garmezy. Development and Psychopathology 24: 333-334.

Masten, Anne. S., Karen Best, and Norman Garmezy. 1990. Resilience and Development: Contributions From the Study of Children Who Overcome Adversity. Development and Psychopathology 2: 425-444.

Norris, Fran. H., Susan P. Stevens, Betty Pfefferbaum, Karen F. Wyche, and Rose L. Pfefferbaum. 2008. Community Resilience as a Metaphor, Theory, Set of Capacities, and Strategy for Disaster Readiness. American Journal of Community Psychology 41(1-2): 127-150.

Olsson, Lennart, Anne Jerneck, Henrik Thoren, Johannes Persson, and David O’Byrne. 2015. Why Resilience Is Unappealing to Social Science: Theoretical and Empirical Investigations of the Scientific Use of Resilience. ScienceAdvances 1(4), https://www.ncbi.nlm.nih.gov/pmc/articles/ PMC4640643 (15.09.2016).

Orgad, Shani. 2009 The Survivor in Contemporary Culture and Public Discourse: A Genealogy. Communication Review 12(2): 132-161.

Richardson, Glenn E. 2002. The Metatheory of Resilience and Resiliency. Journal of Clinical Psychology 58(3): 307-321.

Rutter, Michael. 1999. Resilience as the Millenium Rorschach: Response to Smith and Gorrell Barnes. Journal of Family Therapy 21(2) : 159-160.

Rutter Michael, 1985. Resilience in the Face of Adversity - Protective Factors and Resistance to Psychiatric Disorder. British Journal of Psychiatry 147: 598-611.

Simonds, Wendy. 1992. Women and Self-Help Culture: Reading Between the Lines. New Brunswick, N. J.: Rutgers University Press.

Sontag, Susan. 1990. Illness as Metaphor. New York: Penguin Books.

Southwick, Steven M., George A. Bonanno, Ann S. Masten, Catherine Panter-Brick, and Rachel Yehuda. 2014. Resilience Definitions, Theory, and Challenges: Interdisciplinary Perspectives. European Journal of Psychotraumatology 5, https://www.ncbi.nlm.nih.gov/pmc/articles/PMC4185134/ (15.09.2016).

Tisseron Serge. 2005. La résilience. Paris: PUF.

Tugade, Michele M., Barbara L. Fredrickson, and Lisa Feldman Barrett. 2004. Psychological Resilience and Positive Emotional Granularity: Examining the Benefits of Positive Emotions on Coping and Health. Journal of Personality 72: 1161-1190.

Ungar, Michael. 2008. Resilience Across Cultures. British Journal of Social Work 38(2): 218-235.

Werner, Emily E. and Smith, R.S. 1982. Vulnerable But Invicible: A Longitudinal Study of Resilient Children and Youth. New York: McGrawHill.

Winch, Peter. 2009 [1958]. L’idée d'une science sociale et sa relation à la philosophie. Paris: Gallimard.

Winch, Peter. 1964. Understanding a Primitive Society. American Philosophical Quarterly 1: 307-324.

Wittgenstein, Ludwig. 2010 [1953]. Recherches philosophiques. Paris: Gallimard.

Woods, Angela. 2013. Rethinking "Patient Testimony." Journal of Literature and Science 6: 38-54. 